\title{
An Investigation of the Wetting Behavior of Heat-Treated Silicon Nitride Particles with
}

\section{Liquid Silicon}

\author{
M. Yasseri ${ }^{1,2,3 *}$, T. Jau $\beta^{1}$, T. Sorgenfrei ${ }^{1}$, A. Cröll ${ }^{1,4 *}$ \\ ${ }^{1}$ University of Freiburg, Crystallography, Hermann-Herder-Straße 5, 79104 Freiburg, Germany \\ ${ }^{2}$ Institute of Materials Research, German Aerospace Center (DLR), Linder Höhe, 51147 Köln, Germany \\ ${ }^{3}$ Institute for Inorganic and Analytical Chemistry, Justus-Liebig University Giessen, Heinrich-Buff-Ring 58, \\ 35392 Gießen, Germany \\ ${ }^{4}$ RSESC, University of Alabama in Huntsville, 301 Sparkman Dr., Huntsville, AL 35899, USA \\ *Corresponding Author(s): Mohammad.Yasseri@dlr.de, Arne.Croell@uah.edu
}

\section{Highlights}

Heat treatment of $\mathrm{Si}_{3} \mathrm{~N}_{4}$ powders over the melting point of $\mathrm{Si}$ ensures their wetting. Wetting of $\mathrm{Si}_{3} \mathrm{~N}_{4}$ in $\mathrm{Si}$ was investigated by sessile drop and float zone experiments. Making $\mathrm{Si}_{3} \mathrm{~N}_{4}$ particles wetting allowed studying their incorporation behavior in $\mathrm{Si}$. To suppress incorporation of $\mathrm{Si}_{3} \mathrm{~N}_{4}$ impurities in $\mathrm{Si}$, the melt must not be superheated.

\begin{abstract}
Silicon nitride is commonly used as a coating material for the silica crucibles utilized for the growth of multicrystalline silicon by directional solidification. The coating material might introduce impurities into the silicon melt during the growth. To investigate the wetting and incorporation behavior of the silicon nitride particles, silicon nitride particles were put intentionally into silicon rods, which were then grown by the float zone technique. To ensure that the particles stay within the melt and are not pushed out of the molten zone, the particles must show good wetting. Superheating the silicon nitride powders up to $105 \mathrm{~K}$ over the melting point of silicon was a successful approach to ensure wetting and thus to investigate the incorporation behavior of the silicon nitride in photovoltaic silicon. The heat treated silicon nitride particles stayed within the melt zone during the float zone experiments and the distribution behavior of the particles could be studied. Incidentally,
\end{abstract}


the results imply that to suppress incorporation of silicon nitride particles (as coating material) into molten silicon during directional solidification, superheating the melt must be avoided.

Keywords: A1. Wetting behavior; A2. Particle engulfment; A2. Silicon nitride coating; B2. Multicrystalline silicon; A2. Floating zone technique; B3. Solar cells.

\section{Introduction}

Photovoltaic devices have attracted considerable attention in recent decades to utilize solar energy, one of the most efficient and environmentally friendly renewable energy sources [1]. Among different kinds of photovoltaic technologies, crystalline silicon-based solar cells have been the most used devices in the industry up to now [2]. Directional solidification is utilized worldwide to produce multicrystalline silicon. Despite the lower efficiency of multicrystalline silicon, it is an attractive method due to the lower manufacturing costs compared with the growth methods for single crystalline silicon [3]. During the directional solidification process for production of multicrystalline silicon, the furnace atmosphere, feed material, crucible, and the crucible coating may introduce impurities into the silicon melt [4]. In directional solidification, two main requirements have to be fulfilled. First, the crucible material should be inert and have negligible reactivity in order to avoid contamination of the melt and short crucible lifetime. Secondly, the material to be grown should not stick to the crucible walls, i.e. the melt must show non-wetting behavior to obtain a spontaneous detachment of the grown crystal from the crucible walls under the effect of thermo-mechanical stresses [5,6]. Sintered silica is commonly used as the crucible material for directional solidification of silicon. Silica is a compromise material used for crucibles in silicon directional solidification processes. However, the melt sticks to the crucible at the $\mathrm{Si} / \mathrm{SiO}_{2}$ interface. Therefore, a coating is needed as an interface releasing agent to provide a spontaneous detachment after growth [7]. Partially oxidized silicon nitride is a widely used coating material for the sintered silica crucible that is utilized in directional solidification, as it leads to a non-wetting behavior of the silicon melt in contact with the crucible wall $[7,8]$. However, the silicon nitride coating introduces nitrogen as an 
impurity into the melt [4]. It leads to the formation of silicon nitride precipitates, often together with silicon carbide precipitates, which cause short circuits in the silicon solar cells and severe problems during the wire sawing of wafers [9-13]. To avoid this, the incorporation behavior of the silicon nitride particles into the silicon melt must be investigated. The incorporation behavior might depend on the growth rate $(\mathrm{v})$, temperature gradient $(\mathrm{G})$, and the particle size $[3,14,15]$. The particles might be pushed by the solidification front or engulfed [16]. Convection and the gravity forces might also affect the particle incorporation behavior [17]. To investigate the incorporation behavior, $\mathrm{Si}_{3} \mathrm{~N}_{4}$ particles (Type-1 and Type-2, see section 2) were put intentionally into silicon rods, which were then grown by the float zone technique. In Fig. 1 the results of the float zone experiments with the silicon nitride powders are presented. In both cases where the virgin Type- 1 and Type- 2 powders were used as depot materials in the CZ-01 and CZ-02 silicon rods, the particles were pushed out of the floating zones, proving a nonwetting behavior of the silicon melt for both virgin Type- 1 and Type-2 particles.

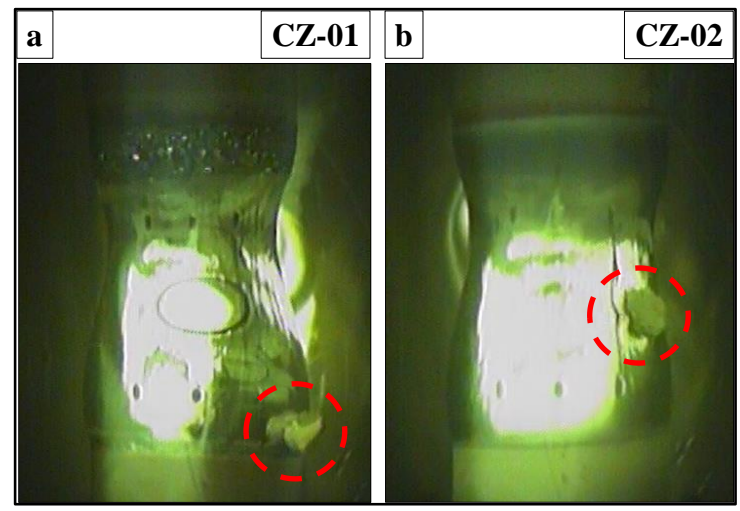

Fig. 1. The floating zone of the samples CZ-01 and CZ-02. The pushed out Type-1 particles (a) and the Type2 particles (b) on the zone are indicated by the dashed circles.

To investigate the incorporation behavior, the particles must stay within the melt. To ensure that the particles are not pushed out of the molten zone, the particles must therefore show good wetting behavior. Making the silicon nitride particles wetted by the silicon melt was possible, but challenging. A high temperature treatment was developed to overcome the non-wetting behavior of the silicon nitride particles. 
A wide range of values was reported as the wetting angle for the $\mathrm{Si}_{3} \mathrm{~N}_{4}$ coating in the literature [7, 18]. This wide range of contact angles is related to the influence of the oxygen partial pressure on the formation of silicon oxynitrides on the silicon nitride coating [5,18]. Reaction 1 and 2 below are reported by Riley where $\mathrm{Si}_{3} \mathrm{~N}_{4}$ is oxidized and as a result either $\mathrm{Si}_{2} \mathrm{~N}_{2} \mathrm{O}$ or $\mathrm{SiO}_{2}$ is formed [19]. Thereafter, the $\mathrm{Si}_{2} \mathrm{~N}_{2} \mathrm{O}$ can be again deoxidized and transformed into $\mathrm{Si}_{3} \mathrm{~N}_{4}$ through reaction 3 [20]. Also, according to the ternary phase diagram of the $\mathrm{Si}-\mathrm{N}-\mathrm{O}$ system, if $\mathrm{Si}, \mathrm{N}_{2}$, and $\mathrm{O}_{2}$ are present in the system as reactants, in regions with high silicon content, $\mathrm{Si}$ is in equilibrium with $\mathrm{Si}_{3} \mathrm{~N}_{4}$ and $\mathrm{SiO}_{(\mathrm{g})}$ [21]. It explains the existence of fine dispersed silicon in the $\mathrm{Si}_{3} \mathrm{~N}_{4}$ coating material. Under this condition, an active oxidation of silicon happens through the reaction 4 , resulting in weight loss for the $\mathrm{Si} / \mathrm{O}_{2}$ system and formation of $\mathrm{SiO}_{(\mathrm{g})}$. There is also the possibility of passive oxidation where $\mathrm{SiO}_{2}$ is formed and a weight gain results through reaction 5 [22,23].

$$
\begin{aligned}
& 2 \mathrm{Si}_{3} \mathrm{~N}_{4}+1.5 \mathrm{O}_{2} \rightleftharpoons 3 \mathrm{Si}_{2} \mathrm{~N}_{2} \mathrm{O}+\mathrm{N}_{2} \\
& \mathrm{Si}_{3} \mathrm{~N}_{4}+3 \mathrm{O}_{2} \rightleftharpoons 3 \mathrm{SiO}_{2}+2 \mathrm{~N}_{2} \\
& 3 \mathrm{Si}_{2} \mathrm{~N}_{2} \mathrm{O} \rightleftharpoons 3 \mathrm{SiO}_{(\mathrm{g})}+\mathrm{N}_{2}+\mathrm{Si}_{3} \mathrm{~N}_{4} \\
& \mathrm{Si}_{(\mathrm{s})}+\mathrm{SiO}_{2(\mathrm{~s})} \rightleftharpoons 2 \mathrm{SiO}_{(\mathrm{g})} \\
& \mathrm{Si}+\mathrm{O}_{2} \rightleftharpoons \mathrm{SiO}_{2}
\end{aligned}
$$

In addition, it is reported that the $\mathrm{Si}_{3} \mathrm{~N}_{4}$ coating became completely wetted by the silicon melt when the temperature is increased to $1580{ }^{\circ} \mathrm{C}$ [22]. Furthermore, Cröll et al. [5] carried out sessile drop experiments using silicon nitride powder as coating material for quartz crucibles. By using vacuum, a contact angle less than $10^{\circ}$ is measured due to deoxidization of silicon oxynitride [5].

In this work, a sessile drop furnace and a float zone furnace were utilized to investigate the wetting and incorporating behavior of the silicon melt being in contact with the silicon nitride particles. The effect of high temperature heat treatment on the wetting behavior of the silicon nitride particles was studied in detail. 


\section{Materials and Methods}

\subsection{Powders}

In this work, two kinds of silicon nitride powders were used (Type-1 and Type-2). Type-1 (Grade SII) powders from the company "H.C. Starck", with a high purity containing $<1$ wt.\% O and $<0.2$ wt.\% $\mathrm{C}$, was obtained by crushing bigger silicon nitride ceramic pieces. Type-2 (SN-7) $\mathrm{Si}_{3} \mathrm{~N}_{4}$ powders from the company "Denka", with a relatively high purity containing $1.5 \mathrm{wt} . \% \mathrm{O}$ and 0.3 wt.\% $\mathrm{C}$, was prepared through direct nitridation of silicon particles by nitrogen gas. Cumulative amounts of other impurities (Fe, Al, and Ca) were lower than 1600 ppm and 6000 ppm in Type-1 and Type-2, respectively. The particle sizes of Type- 1 and Type- 2 were smaller than $10 \mu \mathrm{m}$ and $50 \mu \mathrm{m}$, and d50-values were 8 and $4 \mu \mathrm{m}$, respectively. Both types are commercially available and comparable to the powders used in photovoltaic industry. The powders were heated up to $105 \mathrm{~K}$ over the melting point of the silicon melt with a holding time of one hour. At first, a vacuum of $10^{-5}-10^{-6}$ mbar was obtained using a turbo pump system and then $5 \mathrm{~N}$ argon gas, further purified through an Oxisorb ${ }^{\circledR}$ cartridge resulting in less than $5 \mathrm{ppb} \mathrm{O}_{2}$, was let in the furnace for an ambient pressure of 700 mbar during the superheating. Three oxygen getters type St 707 from the company "SAES Advanced Technologies S.P.A.” were positioned in the furnace to further reduce the partial pressure of $\mathrm{O}_{2}$ to sub-ppb-levels [24] during superheating.

To prepare the substrates for the sessile drop experiments, the powders were set in a shallow $\mathrm{pBN}$ crucible and pressed only with manual force i.e. the substrates had a high porosity and were not like solid sintered silicon nitride ceramics. Both superheated and non-superheated powder slabs were utilized to compare the wetting behavior of silicon in contact with the particles. A polysilicon piece (from the company Wacker) with a weight of $0.5 \pm 0.1 \mathrm{~g}$ was put on each substrate (powder slab). A set of sessile drop experiments was conducted in a temperature range between $1450-1500{ }^{\circ} \mathrm{C}$ to investigate the wetting behavior of the silicon melt on the substrates made of the superheated and non-superheated powders (Type-1 and Type-2). The utilized sessile drop furnace (RHTH 
120/600/16- company Nabertherm) [5] contains a cylindrical tube chamber with two rails made out of heat resistant $\mathrm{Al}_{2} \mathrm{O}_{3}$, on which the sample holder is placed. An optical camera system is utilized to monitor the shape and characteristics of sessile drops. A type $S$ thermocouple is used to measure the temperature near the heaters. At around $1470-1480{ }^{\circ} \mathrm{C}$ some liquid was seen around the silicon piece proving that there is a temperature difference between the furnace heater and the sample, as the melting point of silicon is $1412{ }^{\circ} \mathrm{C}$ [11]. Unfortunately, the need for windows at both ends of the furnace tube for optical observation of the sample precludes the placement of a thermocouple close to or inside the sample. Therefore, the temperatures presented here are higher than the real temperature of the sample by about $60 \mathrm{~K}$. Different samples and the related codes are mentioned in Table 1.

Table 1. Different samples for sessile drop experiments and the related codes.

\begin{tabular}{|c|c|c|}
\hline & Sample & Code \\
\hline 1 & Superheated Type-1/ for Sessile Drop Experiment in Presence of Oxygen Getters & S-T1-G \\
\hline 2 & Non-superheated Type-1/ for Sessile Drop Experiment in Presence of Oxygen Getters & N-T1-G \\
\hline 3 & Superheated Type-2/ for Sessile Drop Experiment in Presence of Oxygen Getters & S-T2-G \\
\hline 4 & Non-superheated Type-2/ for Sessile Drop Experiment in Presence of Oxygen Getters & N-T2-G \\
\hline
\end{tabular}

An X-ray powder diffractometer (Stoe STADI-P) was utilized to investigate the phases of the superheated and non-superheated silicon nitride powders. For optical microscopy and scanning electron microscopy from cross-sections of prepared powder slabs, all samples were embedded with a cold mounting resin (SpeziFix-20 of the Company Struers). Afterwards, the embedded samples were cut by a diamond circular saw where the silicon piece had been located and melted. An optical microscope (Zeiss Axio Imager Z1m) with dark field mode was employed to investigate the silicon melt traces on the surface and in the cross-sections of the substrates. A scanning electron microscope (Leo Gemini 1525 with Oxford X-Max EDX detector) was used to obtain more information about the infiltration behavior of the silicon melt in the substrates. 


\subsection{Crystal growth}

As starting materials, four CZ grown silicon rods (CZ-01, CZ-02, CZ-03, and CZ-04), with an orientation of [100], and one polycrystalline FZ grown silicon rod (FZ-01) were utilized. The oxygen content of FZ grown material is supposed to be less than CZ grown silicon [25]. The silicon rods were phosphorous doped (n-type silicon) and had a length and diameter of $90 \mathrm{~mm}$ and $8 \mathrm{~mm}$, respectively. A peripheral cylindrical depot source was prepared by filling a hole in the middle of each rod (depth $=4.5 \mathrm{~mm}$, diam. $2 \mathrm{~mm}$ ) with a desired amount of Type- 1 or Type- 2 silicon nitride powders (see Table 2) and closing it by spot-melting with focused visible light radiation in a doubleellipsoid float zone furnace [26,27]. In the cases of CZ-04 and FZ-01 some loss of powder was observed during the preparation. Then the rods were mounted in ampoules. The ampoules with a wall thickness of $1.5 \mathrm{~mm}$ and an inner diameter of $19 \mathrm{~mm}$ were made of pure fused quartz. After evacuating to $10^{-5}$ mbar, argon gas was backfilled into the ampoule and the ampoule was closed using an $\mathrm{H}_{2}-\mathrm{O}_{2}$ flame.

Table 2. Type and weight of the samples.

\begin{tabular}{|c|c|c|c|}
\hline Sample & $\begin{array}{c}\text { Type of the } \\
\text { Grown Rod }\end{array}$ & Type of the Powder & $\begin{array}{c}\text { Weight of the } \\
\text { Powder [mg] }\end{array}$ \\
\hline CZ-01 & N-type/ CZ & Non-Superheated Type-1 & 1.52 \\
\hline CZ-02 & N-type/ CZ & Non-Superheated Type-1 & 1.71 \\
\hline CZ-03 & N-type/ CZ & Superheated Type-1 & 1.92 \\
\hline CZ-04 & N-type/ CZ & Superheated Type-2 & 4.90 \\
\hline FZ-01 & N-type/ FZ & Superheated Type-2 & 4.03 \\
\hline
\end{tabular}

The particle incorporation experiments were carried out in a monoellipsoid float zone furnace [28], the ampoule was placed in the furnace and the rotation speed was set to $12 \mathrm{rpm}$. To have a stable float zone, a heating power of about 550- $700 \mathrm{~W}$ and a vertical translation speed in the downward direction $(2-10 \mathrm{~mm} / \mathrm{min})$ were applied to the system in different periods of time. After the float zone 
experiment, each sample was cut axially to obtain a slab with a thickness of $2.5 \mathrm{~mm}$ from the middle part of the formed float zone. Thereafter, the samples were ground and polished. Fig. 2 shows one of the rods in the ampoule after the growth and the cut crystal.

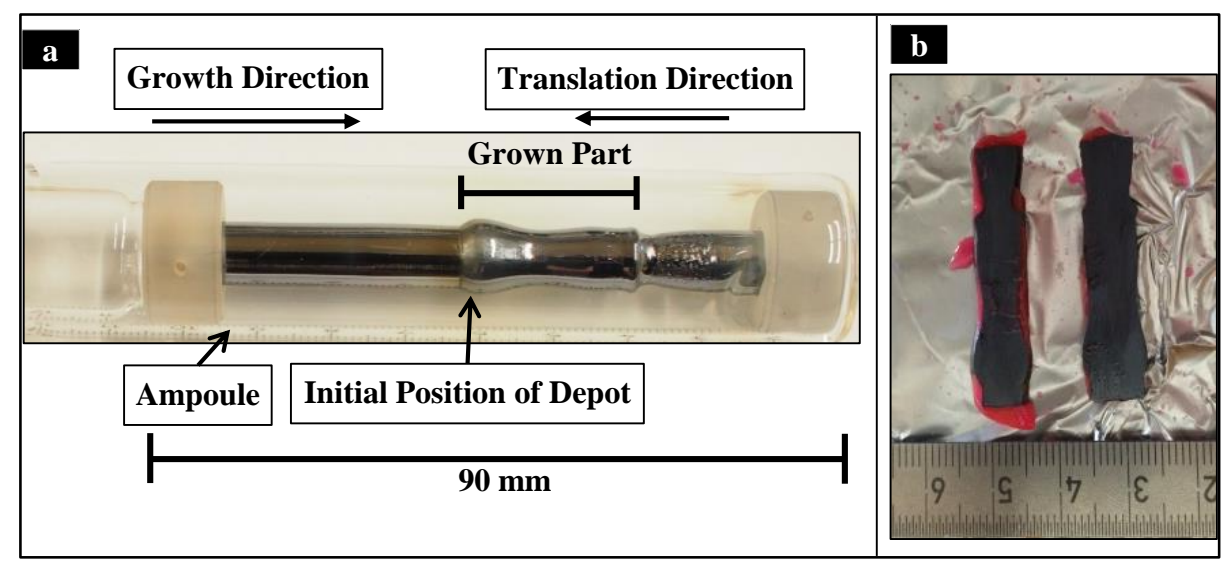

Fig. 2. One of the silicon rods in the ampoule after the growth (a) and the cut crystal (b). The initial position of depot and the grown part are indicated.

Infrared micrographs with an overview of the samples were made to investigate the distribution of the incorporated particles and the precipitates in the crystals.

\section{Results and Discussion}

\subsection{Powders}

Fig. 3 shows the XRD patterns of the powders. The non-superheated Type-1 powder (N-T1-G) contains two hexagonal phases of $\alpha-\mathrm{Si}_{3} \mathrm{~N}_{4}(67.3 \%)$ and $\beta-\mathrm{Si}_{3} \mathrm{~N}_{4}(29 \%)$. This powder also contains some amounts of silicon oxynitride (or silicon oxide nitride) and silicon with volume percentages of $3 \%$ and $0.7 \%$, respectively. The silicon oxynitride phase leads to high contact angles and nonwetting behavior where the silicon melt is in contact with the particles [29]. 


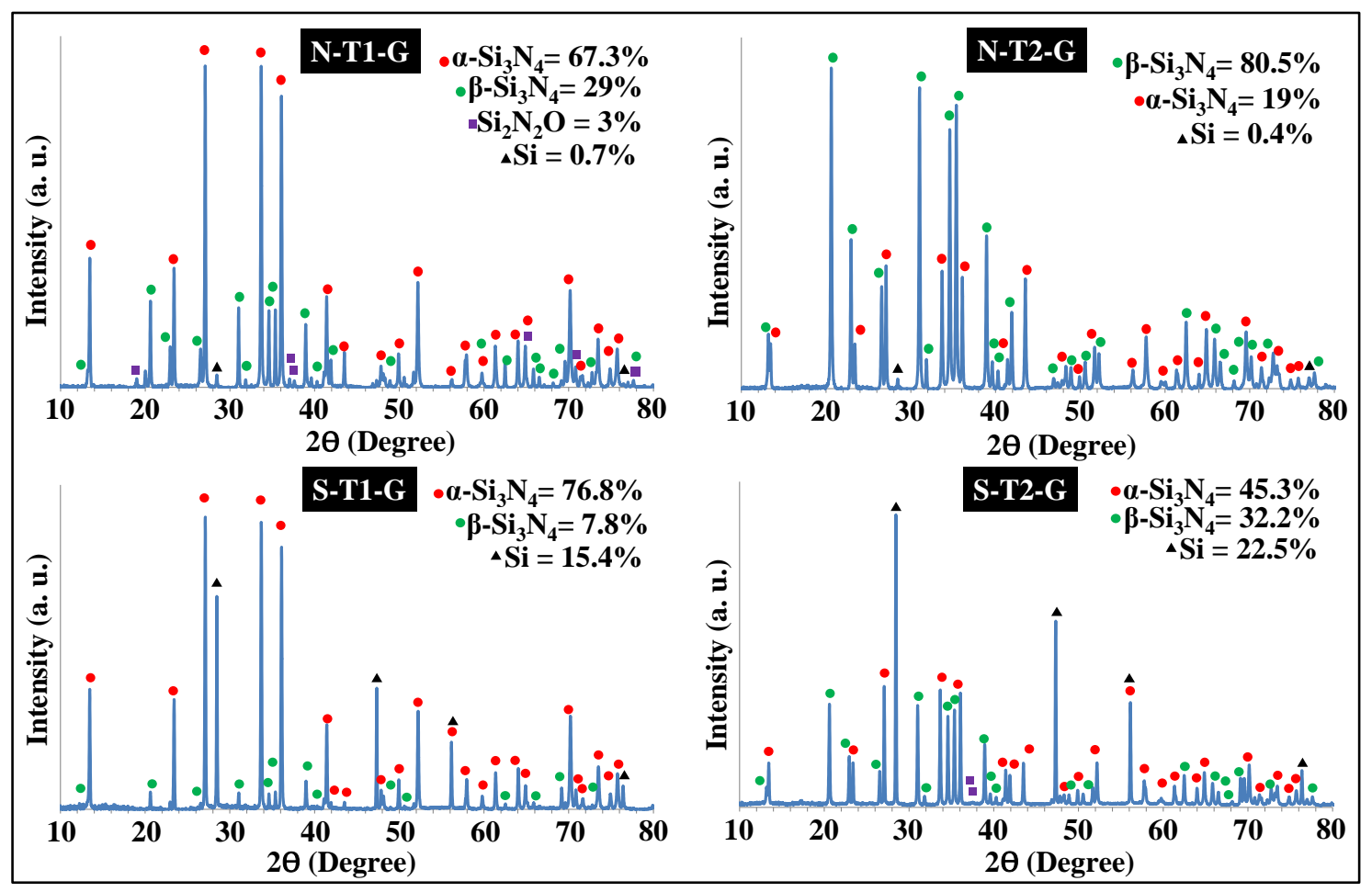

Fig. 3. XRD patterns of the powders N-T1-G, N-T2-G, S-T1-G, and S-T2-G.

By superheating the powders up to $105 \mathrm{~K}$ over the melting point of silicon, the volume percentages of $\alpha-\mathrm{Si}_{3} \mathrm{~N}_{4}$ and $\beta-\mathrm{Si}_{3} \mathrm{~N}_{4}$ changed to $76.8 \%$ and $7.8 \%$, respectively (S-T1-G). Also, the volume percentage of the silicon phase increased considerably to $15.4 \%$. The most important difference between the XRD results of the superheated and the non-superheated Type-1 powders is that the silicon oxynitride phase is eliminated by superheating.

The XRD results of non-superheated Type-2 powder $(\mathrm{N}-\mathrm{T} 2-\mathrm{G})$ shows that it contains $\beta-\mathrm{Si}_{3} \mathrm{~N}_{4}, \alpha-$ $\mathrm{Si}_{3} \mathrm{~N}_{4}$ and silicon with volume percentages of $80.5 \%, 19 \%$, and $0.4 \%$, respectively. By superheating the powders, the volume percentages of $\alpha-\mathrm{Si}_{3} \mathrm{~N}_{4}, \beta-\mathrm{Si}_{3} \mathrm{~N}_{4}$ and silicon changed to $45.3 \%, 32.2 \%$, and $22.5 \%$ respectively. The XRD results of non-superheated Type-2 powder (N-T2-G) shows that it contains $\beta-\mathrm{Si}_{3} \mathrm{~N}_{4}, \alpha-\mathrm{Si}_{3} \mathrm{~N}_{4}$ and silicon. No silicon oxynitride was detected in the non-superheated silicon nitride powder. By superheating the powders, the total amount of $\mathrm{Si}_{3} \mathrm{~N}_{4}$ decreased and the silicon content increased. It is clear that the amount of the silicon phase increased considerably, as 
there was a decrease in the total quantity of the silicon nitride phases. Using XRD, there is also no crystalline silicon oxynitride phase detected in the powder Type-2.

For sessile drop experiments, powder particles were physically bonded and packed together only with a slight mechanical force, thus the porosity was high. Therefore, the wetting angles which are reported in this paper can only clarify the effect of the superheating in the experiments of this work and are not exactly comparable with the wetting angles that were reported in the literature where sintered silica with silicon nitride coating was used [5,6,18,30,31].

In all the sessile drop experiments, serial images were taken (Fig. 4) while the silicon piece was being heated on the powder slabs in a temperature range between $1450{ }^{\circ} \mathrm{C}$ and $1500{ }^{\circ} \mathrm{C}$ and a period of $40 \mathrm{~min}$.

In the sessile drop experiment for silicon on the N-T1-G powder slab (Fig. 4a), the melting started at a temperature of $1478{ }^{\circ} \mathrm{C}$. At 00:29 and at a temperature of $1488{ }^{\circ} \mathrm{C}$ the silicon melt had a form similar to a drop and the left-hand side wetting angle (L- wetting angle) was $48^{\circ}$. At $00: 33$ and as the temperature reached $1491{ }^{\circ} \mathrm{C}$, the $\mathrm{L}$ - wetting angle was $35^{\circ}$. The apparent wetting angle decreased to $0^{\circ}$ as the temperature reached $1500{ }^{\circ} \mathrm{C}$. 


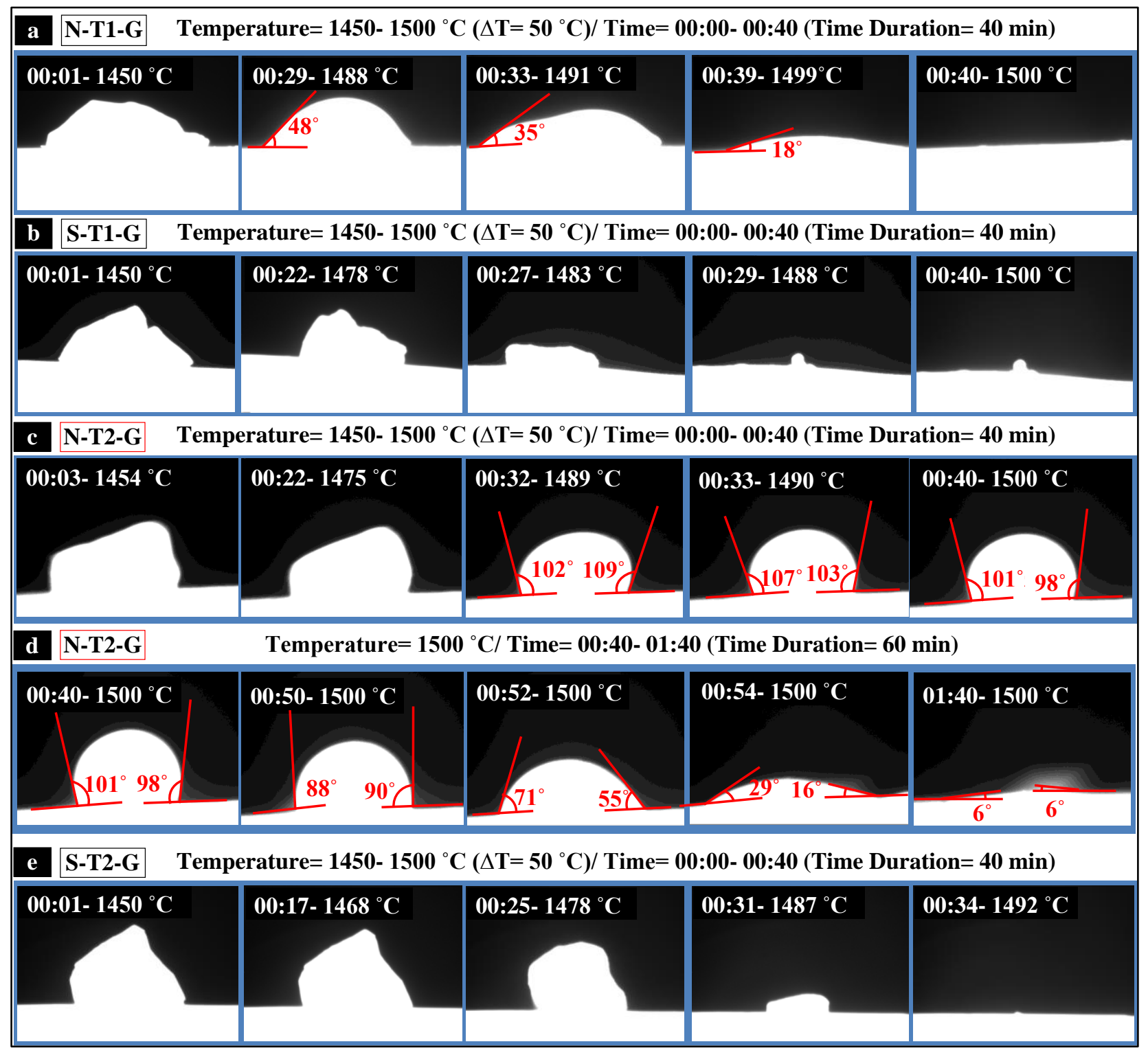

Fig. 4. Sessile drop screen shots of the samples N-T1-G (a), S-T1-G (b), N-T2-G (c and d), and S-T2-G (e).

The time and temperature of each screen shot are respectively mentioned on top.

In the case of the S-T1-G powder slab (Fig. 4b), after the temperature reached $1477{ }^{\circ} \mathrm{C}$ (at $00: 21$ ) the powder slab started soaking up the silicon melt as soon as the melting started. At $1488{ }^{\circ} \mathrm{C}(\mathrm{t}=29$ min), the silicon melt infiltrated completely into the powder except for a tiny part that remained on the surface of the powder slab. In this temperature range, no drop was formed and the only wetting angle which can be reported for this experiment is $0^{\circ}$.

Fig. 4c shows different screenshots for N-T2-G powder slab, which were taken in a temperature range between $1450{ }^{\circ} \mathrm{C}$ and $1500{ }^{\circ} \mathrm{C}$ and in a period of $40 \mathrm{~min}$. After 22 minutes and at $1475{ }^{\circ} \mathrm{C}$ the 
silicon piece started melting and at 00:32 $\left(1489^{\circ} \mathrm{C}\right)$, a drop of silicon melt formed on the powder. At 00:40 and as the temperature reached $1500{ }^{\circ} \mathrm{C}$, the left and right-hand side wetting angles were $101^{\circ}$ and $98^{\circ}$, respectively indicating a non-wetting behavior. The experiment was continued for the period of one hour when the temperature of the furnace thermocouple was constant at $1500{ }^{\circ} \mathrm{C}$ (see Fig. 4d). The wetting angles had more or less stable values in the first 12 minutes of the holding time. Then a rapid decline was experienced in the both left and right-hand side wetting angles to reach values of $29^{\circ}$ and $16^{\circ}$ at $00: 54$. These wetting angles decreased to $6^{\circ}$ at the end of the holding period at $1500{ }^{\circ} \mathrm{C}$.

Fig. $4 \mathrm{e}$ shows the result of the sample with the superheated Type-2 powder slab (S-T2-G). At 00:25 and $1478{ }^{\circ} \mathrm{C}$, the silicon piece started to melt and infiltrate the powder slab and at $1492{ }^{\circ} \mathrm{C}$ and $00: 33$ it was completely infiltrated into the powder. No drop was formed during the melting of the silicon. According to the XRD results, there was a small amount of silicon present in the structure of the non-superheated particles (Type-1 and Type-2). If the silicon melt is present in a silicon oxynitride surrounding and the temperature exceeds the melting point of silicon by at least $105 \mathrm{~K}$, the oxynitride phase converts to silicon nitride and silicon monoxide (g) that leads to lower contact angles [29]. If there is oxygen present in the ambient atmosphere, $\mathrm{Si}_{3} \mathrm{~N}_{4}$ is oxidized and as result either $\mathrm{Si}_{2} \mathrm{~N}_{2} \mathrm{O}$ or $\mathrm{SiO}_{2}$ are formed through reactions $\mathrm{R} 1$ and $\mathrm{R} 2$ [19]. As the argon was flowing during the superheating experiment and there were oxygen getters present in the sessile drop furnace, it is possible that the amount of oxygen was smaller in the vicinity of the particles, which slows down the reaction. There is also the possibility that $\mathrm{Si}_{2} \mathrm{~N}_{2} \mathrm{O}$ is deoxidized and transformed into $\mathrm{Si}_{3} \mathrm{~N}_{4}$ (through R3). The products of this reversible reaction are silicon monoxide $\left(\mathrm{SiO}_{(\mathrm{g})}\right)$ and silicon nitride [20]. If silicon monoxide is removed from the environment by either flowing argon or oxygen getters, $\mathrm{Si}_{2} \mathrm{~N}_{2} \mathrm{O}$ continues to deoxidize, and the wetting angle decreases. The XRD results of the superheated Type-1 powders confirmed that the silicon oxynitride was eliminated after the superheating, and the amount of silicon was increased to $15.4 \%$. The reason for this would be the reactions R1, R2, and R5 
$[18,19]$ : The silicon oxynitride transforms to silicon nitride and oxygen according to R1 [19]. Some amount of the silicon nitride converts to silicon oxide and nitrogen through R2 if a sufficient amount of oxygen is present [19]. After that, the silicon oxide dissociates to silicon and oxygen according to R5 [22].

As mentioned before, the powder particles were packed together only with a slight mechanical force and the porosity was high. The reason that the silicon melt did not remain drop shaped on the nonsuperheated Type-1 powder slab (N-T1-G) and wetted the surface would be capillary action in the pores between the particles. The silicon melt, as a liquid, went into the pores between the particles of the surface layers which resulted in the wetting angle of $0^{\circ}$ at the end of the period with the temperature range between $1450{ }^{\circ} \mathrm{C}$ and $1500{ }^{\circ} \mathrm{C}$.

The N-T2-G silicon nitride powder slab was not wetted by the silicon at the end of the period with the temperature range between $1450{ }^{\circ} \mathrm{C}$ and $1500{ }^{\circ} \mathrm{C}$ (see Fig. 4c). However, the wetting angle decreased to the final value of $6^{\circ}$ after one hour, as the temperature was constant at $1500{ }^{\circ} \mathrm{C}$. According to the XRD result of the non-superheated Type-2, there was no crystalline silicon oxynitride phase present in the structure above the detection limit of the powder diffractometer. One can say the porosity of the powder slab was low because the particle size distribution of the Type- 2 powder was wide (particles were smaller than $50 \mu \mathrm{m}$ ). The low porosity of the powder slab led to the drop formation and the delay in the wetting behavior of the non-superheated Type- 2 particles which did not have any silicon oxynitride phase. However, according to data provided by the manufacturer of Type- 2 powders, the virgin powders contain $1.5 \mathrm{wt} \%$ oxygen. Therefore, since no crystalline oxynitride phase was detected, it might be possible that an amorphous silicon oxynitride or silicon oxide layer was formed on the surface of the particles but was not detected by XRD. Therefore, due to the presence of this phase on the surface of the particles, the non-superheated Type- 2 powder slab (N-T2-G) was not wetted by silicon until the temperature reached $1500{ }^{\circ} \mathrm{C}$. After some minutes, this phase transformed into the silicon nitride through R1. In other words, a kind of superheating 
happened after the temperature was held at $1500{ }^{\circ} \mathrm{C}$ for 13 minutes. After that, the wetting angle started decreasing. The alternative is that the silicon oxynitride transformed to silicon nitride and gaseous silicon monoxide through $\mathrm{R} 3$ [20] and as the $\mathrm{SiO}_{(\mathrm{g})}$ went away by either argon flow or was attracted by getters, the decrease of the contact angle happened.

Fig. 5 shows the cross sections of the samples S-T1-G, N-T1-G, S-T2-G, and N-T2-G with the dark field mode of the optical microscope after the sessile drop experiments. The powder slabs are surrounded by a dark grayish material which is the embedding material. Each cross section shows underneath the initial position of the silicon piece which was located on the powder slabs.

The silicon infiltration areas are indicated by red dotted lines. The cross sections of the samples $\mathrm{N}$ T1-G and N-T2-G show that the silicon melt is only on the surface of the powder slab or near the surface, which implies that it did not infiltrate deeply. The bulged solidified silicon is obvious in the cross section of the sample N-T2-G which confirms the wetting angle of $6^{\circ}$. The cross sections of the non superheated samples (N-T1-G and N-T2-G), are whitish or slightly grayish where no silicon infiltrated. The cross sections of the samples S-T1-G and S-T2-G show that the silicon melt infiltrated deep into the powder slabs reaching the bottom of the slabs. The color of both types of the silicon nitride powders (S-T1-G and S-T2-G) became grayish and darker by superheating. If the temperature is held at $105 \mathrm{~K}$ above the silicon melting point (superheating), the wetting angle of the silicon melt decreases gradually. As the temperature increases above the melting point of silicon, the silicon evaporates and condenses on the surface of the silicon nitride particles. It results in the formation of a thin gray layer of silicon on the surface of the silicon nitride particles (S-T1-G and ST2-G)) [21,22], leading to the particles being wetted by the silicon melt. Even the particles in the depth of the superheated powder slabs had the tendency to be wetted by silicon. 


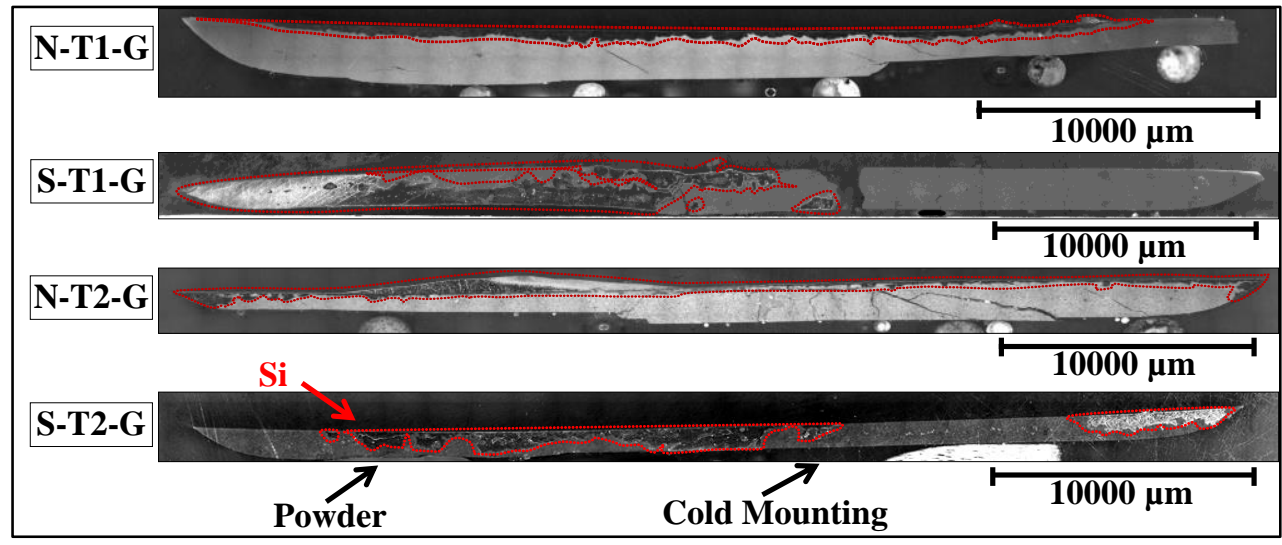

Fig. 5. The cross sections of the samples N-T1-G, S-T1-G, N-T2-G, and S-T2-G (Dark Field View) after the sessile drop experiment. The red dots indicate the infiltration of the silicon in cross sections. The black arrows indicate the powder slab and the cold mounting (embedding material).

Yang et al. [32] investigated the static mechanics requirement for the spontaneous liquid infiltration into orderly packed spheres. It is found that a wetting angle much lower than $90^{\circ}$ is required to achieve a spontaneous infiltration. Considering the theory and assuming that it is in principle also valid for non-spherical particles, it is confirmed that in the case of superheated powders, where a spontaneous and deep infiltration of silicon happened after the melting, the melt had a wetting angle much lower than $90^{\circ}$ in contact with the silicon nitride particles. In addition, in the cases of the nonsuperheated powders (see Fig. 4a and 3c), where a drop formed on the surface of the powder slabs, no spontaneous or deep infiltration happened since the silicon nitride powders were not wettable by the silicon melt. The BSE images of the samples S-T1-G, N-T1-G, S-T2-G, and N-T2-G are shown in Fig. 6. The BSE images also confirm the finding of Yang et al. [32]. Sharp tips in infiltration patterns can be considered as one sign of the spontaneous infiltration. We define here arbitrarily a sharp tip as a melt front with a quasi-ellipse shape in the infiltration pattern where the ellipse aspect ratio (semi-minor axis/ semi-major axis) is lower than 0.5 , given that the major ellipse axis is parallel to the direction of the infiltration.

An interesting view of the N-T1-G powder slab is shown in Fig. 6a. The silicon melt with the light gray color did not infiltrate deeply into the non-superheated Type-1 silicon nitride powder slab. It 
confirms the nonwetting tendency of this kind of silicon nitride powder. The silicon melt flowed smoothly on the surface layers of the powder slab N-T1-G, and there is no sharp tip in the infiltration pattern. The melt is in contact with the powder slab in several points with a curved configuration. This smoothly curved configuration is shown in this figure with white arrows.

It is obvious in a view of the sample N-T2-G (Fig. 6b) that the silicon remained mostly on the surface of the powder slab or near to its surface. A part of the melt has infiltrated into the powder at more depth. However, the infiltration boundary is again curved. All these illustrate the low tendency of the non-superheated particles to be wetted.

Figs. $6 \mathrm{c}$ and $6 \mathrm{~d}$ show views of the cross sections S-T1-G and S-T2-G, respectively. It is obvious that the silicon melt has infiltrated into the bottom of the powder slabs. The silicon melt had the tendency to infiltrate into the superheated silicon nitride powders with a sharp tip configuration in several points. Some of these sharp tips are indicated with the red arrows in both images. The superheating changed the infiltration pattern of the silicon significantly.

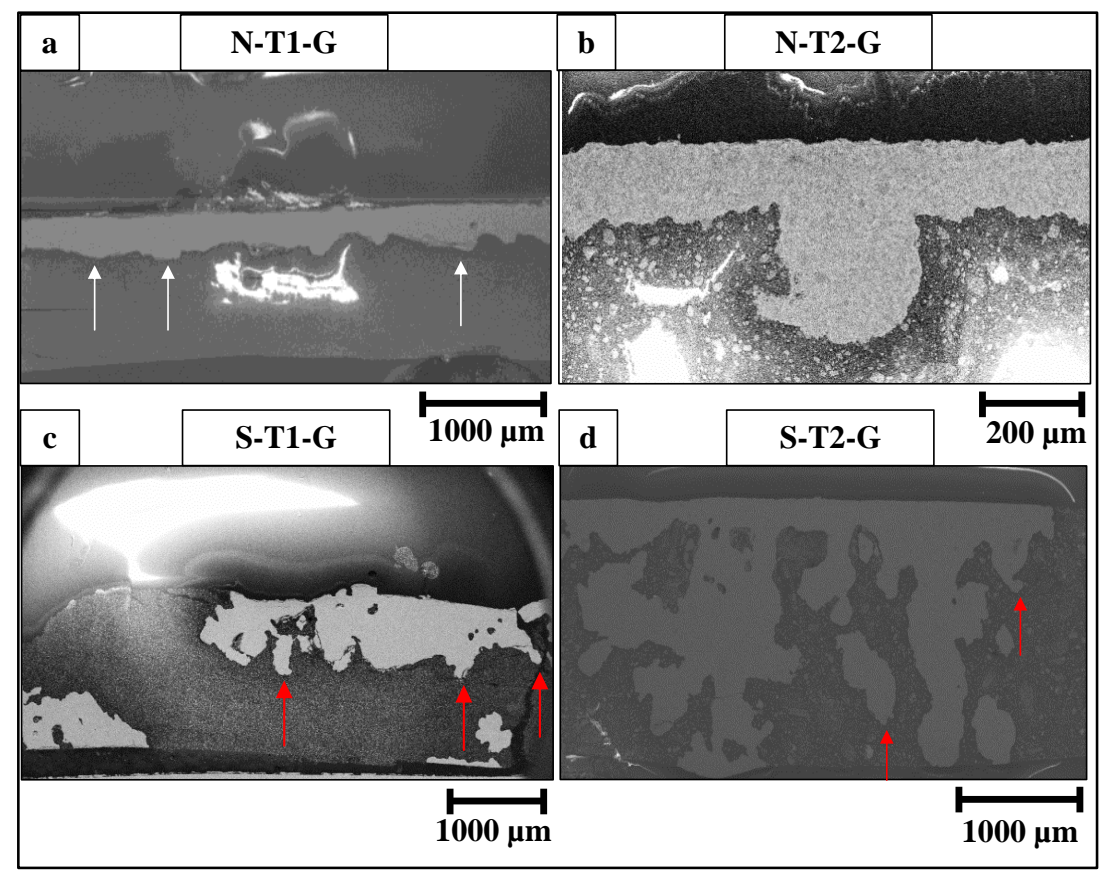

Fig. 6. BSE images of the samples N-T1-G (20X) (a), N-T2-G (30X) (b), S-T2-G (30X) (c), and S-T2-G $(100 X)(d)$. The white areas present in the BSE images are due to charging during the SEM analysis. The 
smoothly curved configuration is indicated with white arrows in Fig. 6a. The red arrows indicate the sharp tips of the infiltration pattern of the silicon melt into the silicon nitride powder slabs in Fig. $6 \mathrm{c}$ and $6 \mathrm{~d}$.

\subsection{Crystal growth}

The results of the float zone experiments with the non-superheated silicon nitride powders (CZ-01 and CZ-02) were presented in the introduction part (Fig. 1). In these cases, silicon nitride particles were pushed out of the ingot. Superheating the silicon nitride powders at around $105 \mathrm{~K}$ above the melting temperature of silicon changed the wetting behavior of the particles. Fig. 7a shows the infrared micrograph of the sample CZ-03, confirming the silicon nitride particles (Superheated Type1) were incorporated into the crystal. The silicon nitride particles stayed in the melt and were not pushed out of the melt zone. The seed and the feed are indicated. The magnified view of the incorporated particles is shown in Fig. 7b. Most of the wetted but non-dissolved particles stayed in the first solidified area.

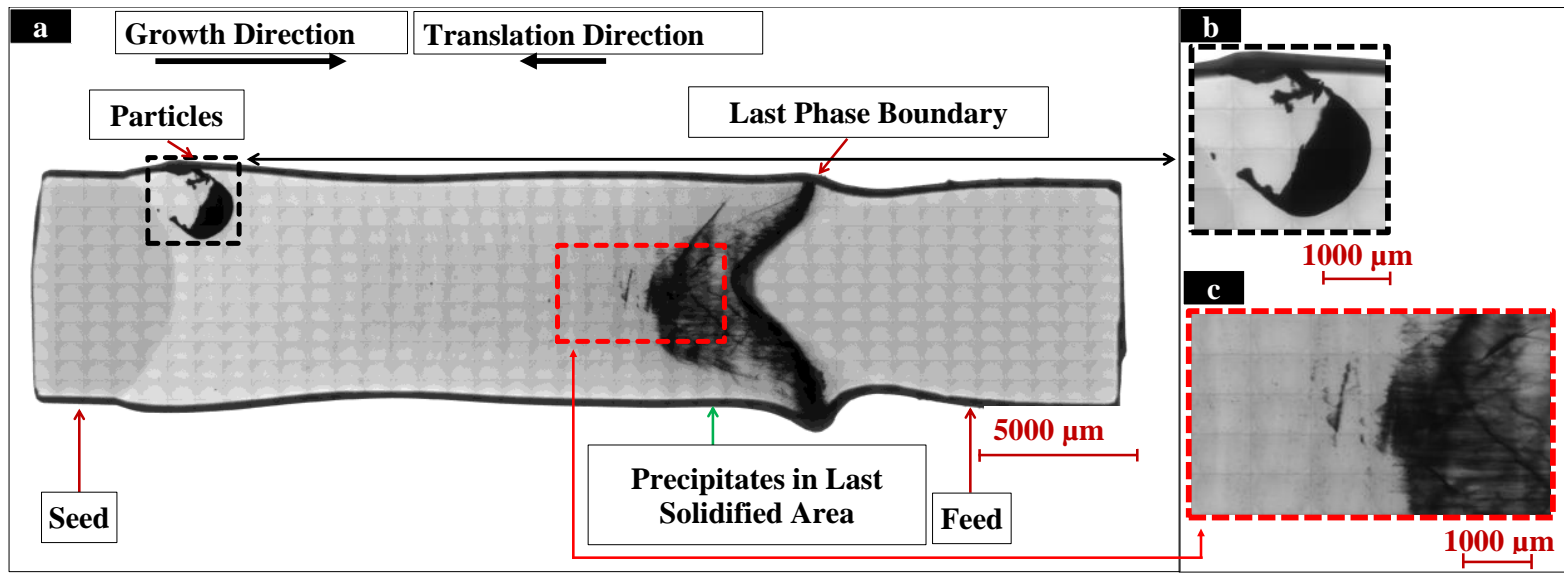

Fig. 7. The infrared micrograph of the sample CZ-03. a) Overall View of the Sample. Images b and c are magnified views from different positions within the crystal. The view $b$ shows the incorporated particles (superheated Type-1) and the view c shows the precipitates within the crystal.

Fig. 8a shows the infrared micrograph of the sample CZ-04. Similar to the last result, the silicon nitride particles (Superheated Type-2) were incorporated into the crystal. Fig. 8b shows a magnified view of the incorporated particles. In this case, the particles are separated more but with different 
sizes. These particles are somehow inhomogeneously distributed in the first strip of the solidified float zone.

Some amount of the wetted silicon nitride particles was dissolved in the molten zone and precipitated later in the last solidified area of CZ-03 and CZ-04 (indicated with red dashed rectangles in Fig. 7a and 8a). There are areas with a number of precipitates in black near the last phase boundary in both samples. Fig. 7c and Fig. 8c show magnified views of these precipitates. The precipitates in the last grown area are segregated silicon nitride precipitates. As the segregation coefficient of the nitrogen is smaller than one $\left(\mathrm{k}_{0}(\mathrm{~N})=0.0007\right)$, it prefers to remain in the melt [34]. Therefore, the melt was saturated with nitrogen and the dissolved nitrogen atoms were transported with the moving zone during the crystallization. As the last float zone was solidified rapidly while finishing the experiment, the melt volume decreased and got supersaturated with nitrogen. Therefore, the silicon nitride precipitates were formed in the last solidified area and the solidification completed. Some of the precipitates are filament-shaped (Fig. 7c and Fig. 8c). The filament shape was reported for $\mathrm{Si}_{3} \mathrm{~N}_{4}$ precipitates in the literature [33].

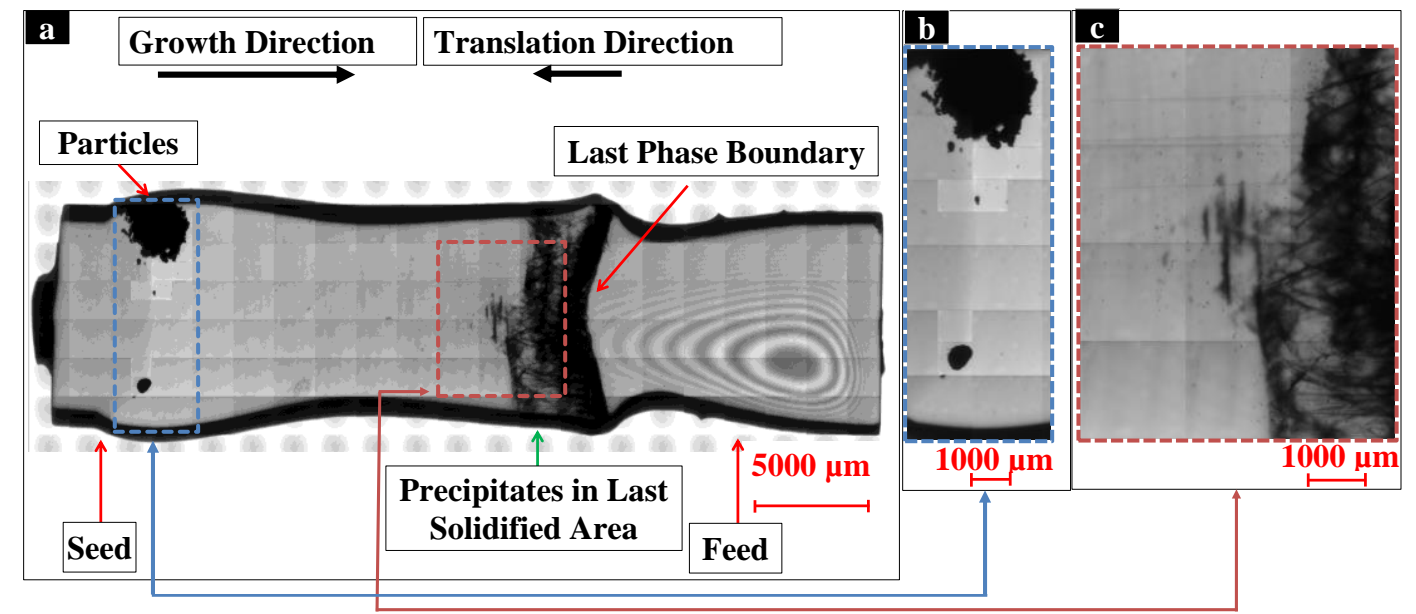

Fig. 8. Infrared micrograph of sample CZ-04. a) Overall view of the sample. Views b and c, are the magnified views from the different positions within the crystal. The view b shows the incorporated particles (superheated Type-2), and the view c shows the precipitates close to the last phase boundary. 
In the sample (CZ-03) the incorporated particles were bulky and were not distributed throughout the sample (Fig. 7). There is a possibility that the oxygen content of the $\mathrm{CZ}$ grown silicon rods made the particles non-wetting after being incorporated. This secondary non-wetting behavior might not let the particles be distributed into the silicon melt. The incorporated particles of the superheated Type- 2 powders were also condensed and stayed in the first solidified area of the CZ-04 (Fig. 8b). All in all, by superheating the silicon nitride particles, they remained in the ingots (CZ-03 and CZ-04), dissolved into the melt to some degree, and reprecipitated in the last solidified section.

To investigate the effect of the oxygen content on the distribution of the silicon nitride particles, a float zone grown rod (FZ-01) was used as starting material. Fig. 9 shows different micrographs of the sample FZ-01. Fig. 9b shows the superheated Type-2 powders.

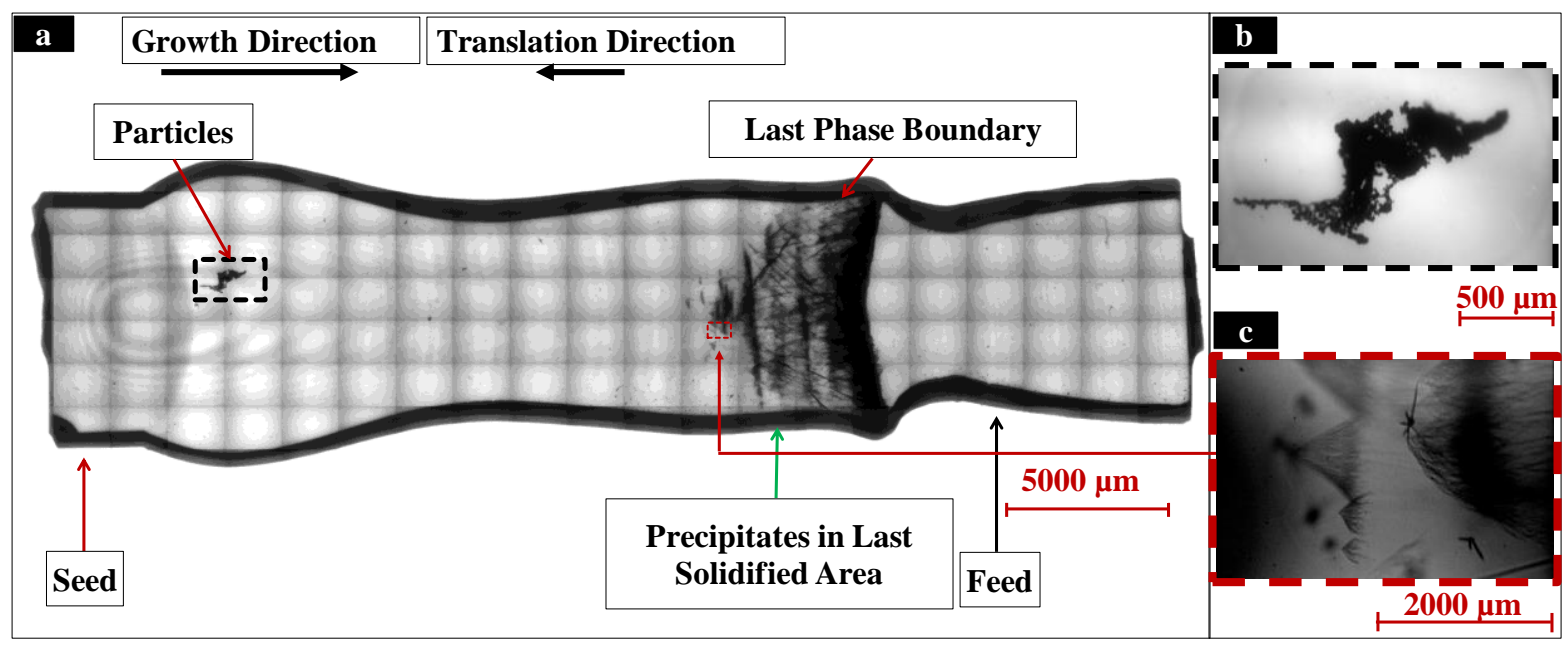

Fig. 9. Infrared micrograph of the sample FZ-01. The superheated Type-2 particles are shown in the image

(b). The view (c) shows the filament-shaped precipitates near to the last phase boundary.

In this case, a considerable part of the silicon nitride particles was dissolved (and dispersed) into the melt which resulted in the formation of precipitates in the last solidified area of the grown crystal (indicated with a green arrow in Fig. 9a and magnified in Fig. 9c). The non-dissolved parts of the silicon nitride particles are not condensed that much (there is some space between the particles). Furthermore, the non-dissolved particles stayed near the central axis of the rod (indicated with a black dashed rectangle in Fig. 9a and magnified in Fig. 9b) and did not show any tendency to be 
repelled by the melt and get stuck to the internal side of the rod wall. Therefore, the lower amount of oxygen in the float zone grown rod (FZ-01) might have an influence on the transportation and distribution of the superheated silicon nitride particles, as the Type-2 particles show a more pronounced wetting behavior in the sample FZ-01 compared with the sample CZ-04, where a CZ grown crystal with higher amount of oxygen was used as starting material of the crystal growth experiment.

\section{Conclusions}

Superheating silicon nitride powders by $105 \mathrm{~K}$ above the melting point of silicon led to the silicon nitride particles being wetted by the silicon melt. The silicon melt infiltrated both the superheated Type-1 and Type-2 powder slabs (substrates) during sessile drop experiments. The float zone experiments confirmed that the superheated silicon nitride particles show good wetting behavior and stay within the silicon melt. This behavior is obtained as the silicon oxynitride content is eliminated by the superheating. Also oxygen content of the melt might have an influence on the distribution and dissolution of the silicon nitride particles, as higher oxygen content might lead to formation of a silicon oxynitride layer on the particles, therefore, reduced wetting. The results confirm that to improve the quality of multicrystalline silicon grown by directional solidification in silica crucibles coated by silicon nitride, to improve efficiency of the industrial photovoltaic silicon, superheating the molten silicon at temperatures above its melting point must be avoided to suppress the incorporation of silicon nitride particles into the silicon melt and reduce the dissolution of the silicon nitride.

\section{Acknowledgements}

Many thanks go to L. Rees-Isele, C. Lehmann, M. Kranz-Probst, H.P. Winkler, and W. Drayer for their excellent technical support. We would like to thank A. Danilewsky for his support in SEM analysis. Also, we owe thanks to C. Reimann, J. Friedrich, and M. Lang from Fraunhofer IISB for providing the powders and the infrared micrograph overviews of the samples. Funding for this work 
came from the German Ministry of Economics (BMWi) through DLR under contract no. 50WM1446.

\section{References}

[1] R. Ahrenkiel, Sol. Energy Mater. Sol. Cells. 76 (2003) 243. doi:10.1016/s09270248(02)00277-5.

[2] J.K. Rath, Sol. Energy Mater. Sol. Cells. 76 (2003) 431. doi:10.1016/s0927-0248(02)00258-1.

[3] F.-M. Kiessling, F. Büllesfeld, N. Dropka, C. Frank-Rotsch, M. Müller, P. Rudolph, J. Cryst. Growth. 360 (2012) 81. doi:10.1016/j.jcrysgro.2012.03.017.

[4] R. Kvande, L. Arnberg, C. Martin, J. Cryst. Growth. 311 (2009) 765. doi:10.1016/j.jcrysgro.2008.09.152.

[5] A. Cröll, R. Lantzsch, S. Kitanov, N. Salk, F.R. Szofran, A. Tegetmeier, Cryst. Res. Technol. 38 (2003) 669. doi:10.1002/crat.200310081.

[6] Y. Maeda, J. Electrochem. Soc. 133 (1986) 440. doi:10.1149/1.2108594.

[7] B. Drevet, R. Voytovych, R. Israel, N. Eustathopoulos, J. Eur. Ceram. Soc. 29 (2009) 2363. doi:10.1016/j.jeurceramsoc.2009.01.024.

[8] V. Schneider, C. Reimann, J. Friedrich, J. Cryst. Growth. 440 (2016) 31. doi:10.1016/j.jcrysgro.2016.02.002.

[9] C. Reimann, M. Trempa, J. Friedrich, G. Müller, J. Cryst. Growth. 312 (2010) 1510. doi:10.1016/j.jcrysgro.2010.02.003.

[10] A. Søiland, E. Øvrelid, T. Engh, O. Lohne, J. Tuset, Ø. Gjerstad, Mater. Sci. Semicond. Process. 7 (2004) 39. doi:10.1016/j.mssp.2004.05.001. 
[11] C. Reimann, M. Trempa, T. Jung, J. Friedrich, G. Müller, J. Cryst. Growth. 312 (2010) 878. doi:10.1016/j.jcrysgro.2009.11.070.

[12] G. Du, N. Chen, P. Rossetto, Sol. Energy Mater. Sol. Cells. 92 (2008) 1059. doi:10.1016/j.solmat.2008.03.007.

[13] O. Breitenstein, J. Bauer, J.P. Rakotoniaina, Semiconductors. 41 (2007) 440. doi:10.1134/s106378260704015x.

[14] J. Pötschke, K. Hohenstein, Acta Astronaut. 9 (1982) 261. doi:10.1016/0094-5765(82)90029-7.

[15] J. Friedrich, C. Reimann, T. Jauss, A. Cröll, T. Sorgenfrei, J. Cryst. Growth. 447 (2016) 18. doi: 10.1016/j.jcrysgro.2016.04.061.

[16] G. Wilde, J.H. Perepezko, Mater. Sci. Eng., A. 283 (2000) 25. doi:10.1016/s09215093(00)00705-x.

[17] G.F. Bolling, J. Cissé, J. Cryst. Growth. 10 (1971) 56. doi:10.1016/0022-0248(71)90046-7.

[18] J.G. Li, H. Hausner, J. Eur. Ceram. Soc. 9 (1992) 101. doi:10.1016/0955-2219(92)90051-e.

[19] F.L. Riley, J. Am. Ceram. Soc. 83 (2000) 245. doi:10.1111/j.1151-2916.2000.tb01182.x.

[20] H. Cheng, Y. Li, E. Kroke, S. Herkenhoff, J. Eur. Ceram. Soc. 33 (2013) 2181. doi:10.1016/j.jeurceramsoc.2013.02.029.

[21] H. Okamoto, J. Phase Equilib. Diff. 26 (2005) 293. doi:10.1361/15477030523571.

[22] I. Brynjulfsen, A. Bakken, M. Tangstad, L. Arnberg, J. Cryst. Growth. 312 (2010) 2404. doi:10.1016/j.jcrysgro.2010.05.006. 
[23] J. Grygowski, G. Rancoule, C. Ndzogha, C. Martin, Search documents, in: 23rd European Photovoltaic Solar Energy Conference and Exhibition, 1-5 September 2008, Valencia, Spain, WIP-Munich, 2008: pp. 1084-1089. doi:10.4229/23rdEUPVSEC2008-2BO.2.2.

[24] A. Dobi, D.S. Leonard, C. Hall, L.J. Kaufmann, T. Langford, S. Slutsky, Y.R. Yen, Nucl. Instrum. Meth. A 620 (2010), 594-598. doi: 10.1016/j.nima.2010.03.151.

[25] G. Dhanaraj, K. Byrappa, V. Prasad, M. Dudley, Handbook of Crystal Growth, Elsevier, Berlin, 2010.

[26] A. Cröll, M. Schweizer, A. Tegetmeier, K.W. Benz, J. Cryst. Growth. 166 (1996) 239. doi:10.1016/0022-0248(96)00059-0.

[27] D. Rivas, J. Sanz, C. Vázquez, J. Cryst. Growth. 116 (1992) 127. doi:10.1016/00220248(92)90122-y.

[28] A. Cröll, M. Schweizer, P. Dold, T. Kaiser, K.W. Benz, M. Lichtensteiger, Adv. Space Res. 29 (2002) 527. doi:10.1016/s0273-1177(01)00661-5.

[29] M. Schumann, Interaktion zwischen flüssigem Silicium und mit Siliciumnitrid beschichtetem Quarz, Ph. D. thesis. University of Freiburg, 2014.

[30] B. Drevet, O. Pajani, N. Eustathopoulos, Sol. Energy Mater. Sol. Cells. 94 (2010) 425. doi:10.1016/j.solmat.2009.10.020.

[31] A. Cröll, N. Salk, F. Szofran, S. Cobb, M. Volz, J. Cryst. Growth. 242 (2002) 45. doi:10.1016/s0022-0248(02)01347-7.

[32] X.F. Yang, X.M. Xi, J. Mater. Sci. 30 (1995) 5099. doi:10.1007/bf00356055.

[33] A. Lawerenz, M. Ghosh, K. Kremmer, V. Klemm, A. Müller, H.J. Möller, Solid State Phenom. 95-96 (2004) 501. doi:10.4028/www.scientific.net/SSP.95-96.501. 
[34] Y. Yatsurugi, N. Akiyama, Y. Endo, T. Nozaki, J. Electrochem. Soc. 120 (1973) 975. doi:10.1149/1.2403610. 